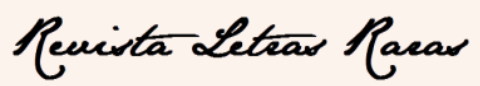

ISSN: 2317-2347 - v. 7, n. 2 (2018)

\title{
O lugar da variação linguística na Base Nacional Comum Curricular $(\mathrm{BNCC})^{1 / T h e}$ place of linguistic variation in the National Curricular Common Base (BNCC)
}

\author{
Luciene Maria Patriota* \\ Paulo Ricardo Ferreira Pereira **
}

\begin{abstract}
RESUMO
$\mathrm{Na}$ esfera educacional, é papel da instituição escolar o desenvolvimento de atividades que propiciem ao aluno o contato com o máximo possível de pluralidade discursiva e situações reais de uso da língua como meio de expandir sua competência comunicativa. Através dessa pluralidade linguística, surgem as variações linguísticas, as quais se adequam ao contexto sociocomunicativo em uso. O presente artigo objetiva apresentar, em linhas gerais, o lugar pensado para o trabalho com a variação linguística na Base Nacional Comum Curricular (BNCC). Nessa direção, colocam-se como objetivos específicos: a) verificar a concepção de língua da BNCC; e b) analisar o lugar da variação linguística nos Anos Finais, do Ensino Fundamental no referido documento. Para isto, alicerçamo-nos em uma metodologia de natureza descritiva e interpretativa com abordagem qualitativa. Teoricamente, partimos das contribuições dos seguintes estudiosos: Alkmim (2004); Antunes (2007); Bagno (2007); Camacho (2004); Tarallo (2007); Travaglia (2002), dentre outros. A partir da análise realizada, constatamos que há sim um lugar para o trabalho com a variação linguística na Base Nacional Comum Curricular, o qual é demarcado como um dos seis objetivos que norteiam e fundamentam a Educação Básica. Apesar disto, o que não há, de fato, é a especificação do como deve ocorrer este trabalho, até porque a Base não se propõe como currículo. Em razão desta ausência metodológica voltada para a aplicação didática, destacamos tanto o papel dos currículos como a postura do profissional docente como elementos determinantes para o processo de ensino-aprendizagem, no que se refere a este fenômeno linguístico.
\end{abstract}

PALAVRAS-CHAVE: Base Nacional Comum Curricular; Concepção de língua; Variação linguística.

\section{ABSTRACT}

In the educational sphere, it is appropriate for the school institution to develop activities that enable the student to contact as much as possible of discursive plurality and real situations of language use as a means to expand his communicative competence. Through this linguistic plurality, linguistic variations emerge, which are adequate to the socio-communicative context in use. The present article aims to present, in general lines, the place thought for the work of Linguistic Variation in the National Curricular Common Base (BNCC). In this direction, the specific objectives are: a) to verify the conception of language of the BNNC and $b$ ) to analyze the place of the linguistic variation in the Final Years, of Fundamental Education, in the mentioned document. For this, we are based on a methodology of descriptive and interpretative nature with a qualitative approach. Theoretically, we start with the contributions of the following scholars: Alkmim (2004); Antunes (2007); Bagno (2007); Camacho (2004); Tarallo (2007); Travaglia (2002), among others. From the analysis carried out, we find that there is a place to work with the linguistic variation in the National Curricular Common Base, which is demarcated as one of the six objectives that guide and base Basic Education. In spite of this, what is not, in fact, is the specification of how this work should take place, not least because the Base is not proposed as a curriculum. Due to this methodological absence, which focuses on the didactic application, we

\footnotetext{
${ }^{1}$ Este trabalho é resultante do projeto de iniciação científica (PIBIC 2016-2017/CNPq/UFCG), no qual foi verificado o lugar da variação linguística na $2^{\circ}$ versão revista da Base Nacional Comum Curricular.

* Doutora em Linguística; Professora Adjunta da Universidade Federal de Campina Grande - UFCG; Campina Grande - Paraíba - Brasil; ene.patriota@yahoo.com.br

** Graduando em Letras-Língua Portuguesa, pela Universidade Federal de Campina Grande - UFCG, Campina Grande - Paraíba - Brasil; paulobtw@live.com
} 


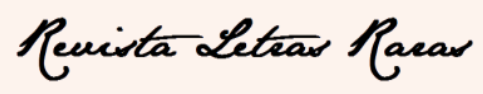

ISSN: $2317-2347$ - v. 7, n. 2 (2018)

highlight both the role of the curricula and the teaching professional's position as determinants for the teaching-learning process, regarding this linguistic phenomenon.

KEYWORDS: National Common Curricular Base; Conception of language; Linguistic variation.

\section{Introdução}

No presente artigo, propomo-nos analisar, em termos gerais, o lugar pensado para a variação linguística, na interface do ensino, no referente curricular tido como base norteadora para a Educação Básica Nacional, a Base Nacional Comum Curricular ${ }^{4}$ (doravante BNCC).

Para respondermos a essa reflexão, partimos da noção de que a forma de conceber as práticas que norteiam o ensino estão alicerçadas em uma determinada concepção de língua, que o estrutura a partir dos documentos que regem o campo de ensino-aprendizagem, os chamados documentos parametrizadores do ensino.

Nesse sentido, à luz de Travaglia (1997), Martelotta (2005), Antunes (2007), Dionísio; Bezerra; Machado (2010), enfatizamos três formas de conceber a língua: como expressão de pensamento, instrumento de comunicação e, por fim, como forma de interação. Na primeira concepção, a língua é relacionada ao funcionamento da mente humana, a qual está enraizada na Gramática Tradicional. Na segunda concepção, a língua é considerada como um código pré-estabelecido, que é dominado por, pelo menos, dois falantes e que, portanto, possibilita os atos de comunicação entre eles. Na última concepção, a língua é compreendida como um meio de realizar ações sobre o interlocutor, concebendo-a, assim, como um lugar de interação, o qual possibilita a troca mútua dos conhecimentos e experiências entre os falantes ${ }^{5}$.

$\mathrm{Na}$ esfera educacional, percebe-se, em verdade, que a abordagem atribuída ao ensino de língua materna encontra-se associada ao ensino prescritivo da língua, isto é, um ensino alicerçado nas regras gramaticais preconizadas pela Gramática Normativa, a qual privilegia veementemente o estudo da norma padrão, padrão aqui na acepção única

\footnotetext{
${ }^{4}$ Este trabalho foi referente à segunda versão revista do documento, que foi divulgada em 2016, sendo que em 2017 foi apresentada a terceira e última versão do documento que foi aprovada em 22 de dezembro de 2017, de acordo com a Resolução CNE/CP, $\mathrm{n}^{\circ} 02$.

${ }^{5}$ Importante atentar para o fato de esses autores citados sistematizam essas concepções com base em abordagens teóricas da Linguística, ou seja, a concepção de língua de diferentes abordagens linguísticas que remontam os gregos - expressão do pensamento; os funcionalistas - língua como instrumento de comunicação; e a linguística do texto e do discurso - concepção de língua como interação.
} 


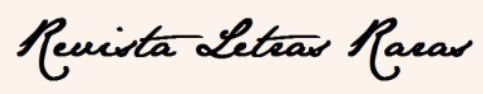

ISSN: $2317-2347$ - v. 7, n. 2 (2018)

e exclusiva de se ensinar gramática normativa, excluindo as demais habilidades e competências sociocomunicativas dos alunos, inseridas nestas as variedades linguísticas oriundas da realidade social de cada um. Neste ensino, enraizado nas concepções de "certo" e "errado", perpetua-se a noção de que existe uma língua tida como padrão, homogênea, que não reconhece a dinamicidade linguística (FARACO, 2008; BAGNO, $2007)^{6}$.

Diante disto, se atribui à escola, enquanto lócus institucional que possibilita a socialização e construção de saberes, um trabalho que não propicia ao aluno o seu desenvolvimento comunicativo em todas as instâncias de uso linguístico, negando-lhe a possibilidade de se formar como pessoas conscientes da complexidade dinâmica e social da linguagem (BAGNO, 2007). A escola centrada apenas no uso padrão da língua, na acepção mostrada anteriormente, termina por não cumprir esse papel.

Assim como as concepções adotadas acerca da língua, o currículo ${ }^{7}$ figura como fator determinante nas práticas escolares, pois é através de sua implementação que as instituições escolares regulamentam os conteúdos, assim como toda dinâmica de ações pensadas para a escola que vão além dos conteúdos a serem trabalhados ao longo de cada etapa de escolarização, seja através das séries, seja através dos anos escolares.

Segundo Goodson (2013), o currículo não atua no vácuo, isto é, na noção de neutralidade. Em sua gênese, ele se fundamenta a partir de concepções sociais, políticas, ideológicas e linguísticas. Neste último caso, a concepção de língua adotada por ele influencia e implica em suas concepções pedagógicas em torno dos objetos e objetivos do ensino de língua.

Nessa direção, a ênfase para o estudo do lugar da variação linguística na BNCC justifica-se, pois, enquanto fator determinante e referente curricular para as práticas escolares, o documento em análise determinará o que será ensinado em cada área de conhecimento e em cada etapa de escolarização englobando todo o país, é através dele que as instituições escolares alicerçarão suas ações pedagógicas

\footnotetext{
6 Leia-se também as coletâneas Norma Linguística e Linguística da Norma (2001, 2002, respectivamente), ambas organizadas por Marcos Bagno para se reforçar a discussão em torno do conceito de "norma".

${ }^{7}$ Estamos tomando currículo aqui na acepção de Arroyo (2013) que o vê como um documento organizado em torno de um núcleo mais estruturante que organiza a dinâmica da escolar, e é também um lugar politizado, inovador e ressignificativo. É o núcleo central das práticas escolares, estruturante por assim dizer, perpassa toda a estrutura da escola, focando desde os conteúdos a serem ministrados em cada ano escolar, até as avaliações do que se ensina, passando por todas as ações pensadas para a realidade escolar. Um currículo, pois, não centrado apenas nos conteúdos.
} 


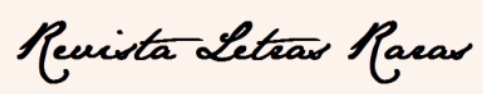

ISSN: $2317-2347$ - v. 7, n. 2 (2018)

Arquitetonicamente, este artigo está estruturado pela presente introdução, que nos revela a gênese do presente estudo, seguida pela fundamentação teórica, na qual apresentaremos um breve recorte sobre os estudos sociolinguísticos, bem como as concepções de língua, destacando-os no campo educacional. Em sequência, analisaremos os resultados encontrados na análise da $2^{\circ}$ versão revista da BNCC (2016) para o lugar da variação linguística. E, por fim, apontaremos as considerações finais.

Metodologicamente, o presente trabalho caracteriza-se como uma pesquisa qualitativa de natureza descritiva e interpretativa. Segundo André (1995, p. 17), a pesquisa descritiva-interpretativa busca "a interpretação em lugar da mensuração, a descoberta em lugar da constatação, a valoração e a indução em lugar da dedução, assume que fator e valores estão intimamente relacionados, tornando-se inaceitável uma postura neutra do pesquisador". Sendo assim, em nossos estudos, procuramos analisar o objeto na linha da descrição e interpretação, nos posicionando sobre ele.

\section{Fundamentação Teórica}

Foi a década de 60 do século XX que representou para os estudos da linguística a chegada da possibilidade de se estudar a língua não numa perspectiva apenas abstrata, mas focalizando seu uso efetivo em situações comunicativas reais, a partir de sua íntima relação com os aspectos sociais, históricos, culturais. A partir dessa data, o princípio básico para o estudo linguístico passou a ser o reconhecimento da inerente heterogeneidade das línguas, trabalho este realizado pelas chamadas correntes da Linguística Moderna. Estavam lançadas as bases para um novo paradigma de análise dos fatos linguísticos.

Dentre essas correntes, temos a Sociolinguística - corrente linguística que tem o objetivo de descrever a língua e seus determinantes sociais e linguísticos, levando em conta seu uso variável (LABOV, 2008; LEITE, 2005; HORA, 2004, p. 18; MOLLICA; BRAGA, 2004; ALKMIM, 2004; CAMACHO, 2004).

O que está no seio das premissas defendidas pelos sociolinguistas, é que, hoje, faz-se necessário "quebrar" a rigidez dos postulados instituídos pelo estruturalismo, revelada nas dicotomias saussurianas língua/fala, sincronia/diacronia, trazendo para 


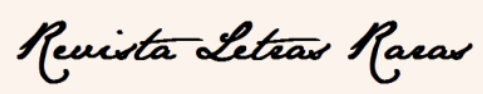

ISSN: 2317-2347 - v. 7, n. 2 (2018)

foco dos estudos a língua em sua realização efetiva, com toda sua heterogeneidade, historicidade, sistematicidade, também.

Em se tratando de um novo paradigma - extremamente frutífero para os estudos linguísticos atuais - a Sociolinguística ou Teoria da Variação e Mudança ou Sociolinguística Quantitativa opera a partir de premissas fundamentais para essa teoria e que podemos considerar como seus postulados básicos, de acordo com Tarallo (2007):

$1^{\circ}$ ) Nem tudo na língua é variação. Mas caso ela exista, não será algo aleatório e sim passível de sistematização;

$2^{\circ}$ ) A partir do reconhecimento da variação, é possível se correlacionar usos diversos com grupos de falantes também diversos socialmente - a chamada estratificação social das variantes;

$3^{\circ}$ ) Também é possível para esta teoria a correlação entre os diversos usos de cada variante em sociedade a depender do contexto no qual se está inserido - a estratificação estilística das variantes;

$4^{\circ}$ ) Toda base de análise a partir de dados empíricos, o chamado "objeto bruto, não-polido, não-aromatizado artificialmente". Parte-se sempre, em estudos desta natureza, do fato linguístico, ele é que revelará se nos encontramos diante de caso de variação estável ou de uma mudança em progresso;

$5^{\circ}$ ) Nem toda variação implica em mudança, mas, diante de um provável caso de mudança, inevitavelmente, temos a presença da variação, no que os sociolinguistas chamam de "embate" - variantes naturalmente em batalha com a "morte" de uma delas.

A partir dessas premissas, a proposta central da Sociolinguística será explicar sistematicamente todo o processo de variação e também de mudança linguística - caso ela esteja, de fato, ocorrendo, reconhecendo a variação como algo inerente a toda língua.

Com os estudos sociolinguísticos, tornou-se possível a distribuição de falantes em diferentes faixas etárias - jovens, meia-idade, idosos. Essa distribuição permite ao investigador perceber usos correlacionados diretamente ao fator idade, ou seja, usos "próprios" de cada grupo, que caracterizam determinada faixa de idade, depois abandonado em detrimento a outros usos.

Além disso, permitiu trazermos para as discussões acerca dos usos da língua, a possibilidade de sua variação também no nível estilístico, ou seja, ao monitoramento 


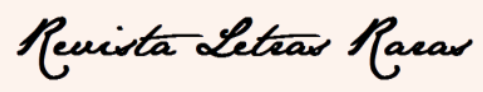

ISSN: $2317-2347$ - v. 7, n. 2 (2018)

feito pelo falante em sua fala a partir das situações de uso dessa língua e da sua interação com outros falantes.

Outro fator de análise trazido pela sociolinguística foi a possibilidade de uso da língua a partir da localização geográfica do falante. Temos assim, os níveis de análise denominados pela Sociolinguística de variação diastrática, diafásica e diatópica ${ }^{8}$ (CAMACHO, 2004).

Com toda essa nova perspectiva, a Sociolinguística traz para o seio das discussões sobre a língua o reconhecimento da relação existente entre língua e sociedade. Ambas estão de tal forma imbricadas que é praticamente impossível imaginá-las separadas uma da outra.

É através de sua língua que o homem faz sua história acontecer, revela suas aptidões políticas e ideológicas, se faz ouvir, convence ou é convencido, revela seu presente, se faz lembrar e projeta seu futuro. Em todos os seus momentos, de vitórias ou derrota, de dúvidas ou convicções, a sua linguagem se faz presente, criando sua história, tornando possível sua sociabilidade (IANI, 1999).

Diante de tal complexidade, faz-se necessária uma abordagem da linguagem, por parte da escola, que explore toda esta riqueza expressiva. Para que isso aconteça, dois requisitos básicos devem estar bem definidos para o ensino de língua: seu objetivo e a concepção que se tem de linguagem.

De acordo com Travaglia (2002), os objetivos para o estudo da língua materna podem ser resumidos em quatro:

O primeiro é aquele considerado mais produtivo para tal ensino, pois engloba uma diversidade de situações de uso da língua que torna seu desenvolvimento mais produtivo. É aquele que visa desenvolver a competência comunicativa do aluno, desde seus domínios linguísticos, até os textuais. Este objetivo de ensino proporciona ao aluno o contato com uma grande variedade de situações de interação comunicativa e abre a escola à vida, havendo, assim, uma maior integração entre escola e sociedade.

O segundo objetivo visa o desenvolvimento do domínio da chamada norma culta/padrão da língua. Muito mais restrito que o primeiro, este objetivo prende-se a

\footnotetext{
${ }^{8}$ Diastrática as variações que têm por base de análise questões de ordem social como faixa etária, escolaridade, classe social, ocupação, gênero, entre outros; Diafásica as variações referentes aos diferentes graus de monitoramento; e Diatópica as variações referentes a questões de ordem geográfica.
} 


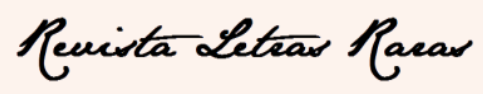

ISSN: $2317-2347$ - v. 7, n. 2 (2018)

uma só modalidade de uso da língua, a escrita. Está voltado somente para as normas gramaticais da língua.

Os terceiro e quarto objetivos ligam-se mais a questões de teoria gramatical e atividades metalinguísticas. Ou seja, conhecer a constituição e funcionamento da língua. São conhecimentos voltados mais para a informação cultural sobre a língua e não propriamente para seu uso efetivo.

Ainda segundo Travaglia (2002), além dos objetivos de ensino, a concepção de língua do professor será essencial para o ensino desta, pois será a partir da forma como se concebe os usos linguísticos que se estruturará seu ensino.

Basicamente, como já apresentamos, a língua pode ser concebida de três formas distintas: como expressão do pensamento, como instrumento de comunicação ou como forma de interação. A primeira forma relaciona a língua ao funcionamento da mente humana, daí considerá-la como um ato monológico que não é afetado pelo meio, nem pelas circunstâncias que envolvem a comunicação. A segunda concepção de língua a vê como um código pré-estabelecido, do domínio de, pelo menos, dois falantes e que permite o ato de comunicação. Já a terceira concepção vê a língua não apenas como um canal de transmissão de pensamento e informação, mas sim como um meio de realizar ações, agir, atuar sobre o interlocutor, ou seja, como um vasto lugar de interação, com trocas mútuas de conhecimentos e experiências por parte dos falantes.

Com relação a esta terceira concepção de língua, Antunes (2007, p.157) ressalta que:

Aceitar as concepções de linguagem - como atividade funcional, interativa, discursiva e interdiscursiva, como prática social situada e imersa na realidade cultural e histórica da comunidade - acarreta visíveis diferenças na vida da escola, consequentemente, no desempenho de professores e alunos. (ANTUNES, 2007, p.157).

Neste sentido, na interface de ensino e aprendizagem, estaríamos desprendendonos do ensino mecanicista, do ensino puramente gramatical, alterando, consequentemente, o foco das aulas - neste caso, das aulas de língua - as quais, segundo Antunes (2007, p.155, grifos do autor), “deixaria de ser a correção para ser $o$ ensino, a exploração, a investigação, a pesquisa, a procura". 


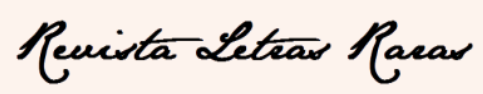

ISSN: $2317-2347$ - v. 7, n. 2 (2018)

Mas o que a prática escolar mostra é algo muito distante do ideal. O principal foco dado ao estudo de língua nas escolas ainda tem sido o do ensino prescritivo da língua, ou seja, aquele ensino voltado para a exploração restrita das chamadas regras da gramática normativa. Um ensino que privilegia, em sala de aula, o estudo da norma padrão da língua em detrimento de todas as demais habilidades linguísticas do aluno (TRAVAGLIA, 2002).

Esta exploração única anula a diversidade de conhecimentos própria da linguagem, que o aluno já traz consigo para a escola. Afinal, para esta forma de ensino existe uma língua padrão, homogênea, suprema, única, correta e que enquadra o homem num padrão social, cultural e político adequado. Nesta concepção de ensino, a teoria do "certo" e do "errado" se estabilizou dentro da escola e elegeu um único uso como sendo o mais valorizado, correto, elegante, capaz de promover socialmente seus usuários, criando assim, o chamado fetichismo da língua e a veneração de um ideal de uso completamente distante do uso real e efetivo da língua (BAGNO 2007).

Vista sob esta ótica, a língua é algo definitivo e absoluto, eliminando todas as demais manifestações e formas de uso, que passam a ser vistas como:

\footnotetext{
Desvios, erros, deformações, degenerações da língua e, por isso, a variedade dita padrão deve ser seguida por todos os cidadãos falantes dessa língua para não contribuir com a degeneração da língua de seu país. (TRAVAGLIA, 2002, p.24).
}

Nessa forma de ensinar a língua, baseada nos usos de escritores consagrados, sem nenhuma base linguística, muitos preconceitos são formados, como: purismo, vernaculidade, classe social de prestígio, autoridade linguística (bom domínio das normas, bom falante!) e tradicionalismo.

Dentre estes preconceitos, o da classe social de prestígio figura como um dos mais fortes, pois inclui no seu interior características de ordem política, econômica e cultural e eleva, a partir da linguagem, alguns à categoria de nobres e outros à categoria de plebeus, povão, analfabetos, excluídos (ALKMIM, 2004, p.39-40).

No entanto, para o ensino de língua materna, o professor deve ter bem fundamentados em sua prática muitos conceitos para que possa entender e ver a língua como um amplo campo de opções de uso e conhecimentos que podem ser apresentados ao aluno. Um desses conceitos, que pode ser considerado como base para todos os 


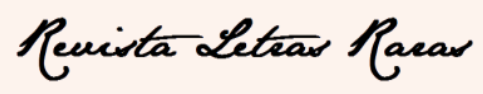

ISSN: 2317-2347 - v. 7, n. 2 (2018)

demais, é a noção de competência comunicativa, que, segundo Leal (1997, p.17) "é a capacidade de reconhecer diversas variedades de linguagem e empregar as mesmas de uma forma adequada, de acordo com a situação e os fins do ato de fala".

Sendo assim, cabe à escola desenvolver atividades que propiciem ao aluno o contato com o máximo possível de pluralidade discursiva e situações reais de uso da língua como meio de expandir a competência comunicativa deste. Através dessa pluralidade discursiva, o aluno terá contato com muitas e variadas situações de uso da língua que, de certa forma, mudarão a tradição que impera em nossa sociedade de considerar a variação algo pejorativo, errado, feio, cômico, ou seja, uma análise quase sempre de ordem negativa. Exigência essa que está entre as principais apresentadas nos documentos que parametrizam o ensino em todas as suas dimensões. Entre esses documentos a Base Nacional Comum Curricular.

A Base Nacional Comum Curricular (2016) é um documento previsto desde a promulgação da Constituição da República Federativa do Brasil, datada em 1988, que, no Art. 210, prevê que "serão fixados conteúdos mínimos para o ensino fundamental, de maneira a assegurar formação básica comum e respeito aos valores culturais e artísticos, nacionais e regionais" (BRASIL, 1988, Art. 210, grifos nossos).

Em 20 de dezembro de 1996, em concordância com a Constituição de 1988, é aprovada a Lei de Diretrizes e Bases da Educação Nacional (LDBEN), Lei 9.394, que, em seu Art. 26, regulamenta que:

Os currículos da educação infantil, do ensino fundamental e do ensino médio devem ter base nacional comum, a ser complementada, em cada sistema de ensino e em cada estabelecimento escolar, por uma parte diversificada, exigida pelas características regionais e locais da sociedade, da cultura, da economia e dos educandos. (BRASIL, 1996, Art. 26, grifos nossos).

Esta parte diversificada, apontada na LDBEN, justifica-se na BNCC como uma forma de manter os aspectos culturais das regiões brasileiras, pois, no documento, mantêm-se o título de "parte diversificada", ao propor $60 \%$ de conteúdos comuns para a educação regular e os outros $40 \%$ constituindo esta parte diversificada, pois abre espaço para a atuação da gestão pedagógica de cada instituição escolar inserir-se como fator determinante no ensino do alunado, possibilitando a este aspectos de sua cultura local. 


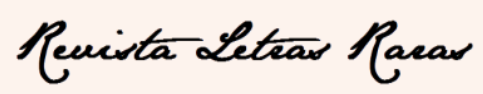

ISSN: $2317-2347$ - v. 7, n. 2 (2018)

Além desta relação com a Constituição Federativa de 88 e a LDB, a BNCC está em consonância também com a política de Diretrizes Curriculares Nacionais (DCN/ 2010), uma vez que atende os pressupostos desse documento e por ser, antes de tudo, um pacto interfederativo (BRASIL, 2016, p.28), cuja matriz possui diversos protagonistas em seu seio de produção, perpassando por órgãos governamentais e pelos cidadãos cívicos, caracterizando-a como um documento resultante de um trabalho coletivo.

Marcando este caráter de trabalho coletivo, a Base foi elaborada e construída com a participação efetiva de 116 especialistas, os quais foram organizados em comissões de acordo com as áreas de conhecimentos e pelos componentes curriculares pertencentes a Educação Básica. Essas comissões foram coordenadas por assessores da Secretaria de Educação Básica do Ministério da Educação e, além disso, foram compostas por representantes de 35 universidades e 2 institutos federais da área de Educação. A Base também contou com a participação de professores das redes públicas estaduais dos 26 estados brasileiros do Distrito Federal, assim como a participação de gestores das redes públicas de ensino. Em sua última etapa de construção colaborativa, a fim de desenvolver a versão definitiva do documento, a comissão organizadora o apresentou através dos Seminários Estaduais, os quais contaram novamente com a participação da comunidade civil - professores, pais, alunos - promovendo, assim, um amplo debate acerca de sua construção e implementação.

Apesar de se propor a ser o alicerce da Educação Básica Nacional, a BNCC não representa o currículo em si, sua finalidade é "orientar os sistemas na elaboração de suas propostas curriculares" (BRASIL, 2016, p.24), respeitando as diversidades (sejam elas de origem social, histórica, cultural) que circundam o alunado. Em razão desta pluralidade, abre-se o espaço para discussões no que tange às variações linguísticas, uma vez que o documento é contra qualquer tipo de discriminação e preconceito e, dentre eles, o preconceito ocasionado em razão dos usos linguísticos: o preconceito linguístico.

Tendo em vista este pensamento voltado para os aspectos de respeito à diversidade que fundamenta o documento, destacamos o trecho a seguir que nos possibilita uma leitura acerca do reconhecimento das variações linguísticas: 


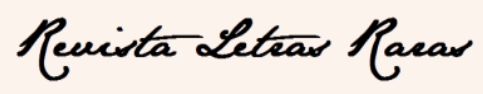

ISSN: 2317-2347 - v. 7, n. 2 (2018)

Se, por um lado, as linguagens aproximam e podem constituir as formas de interação e a identidade cultural de grupos sociais, por outro lado, podem gerar discriminação e conflitos, decorrentes de percepções e representações sobre a realidade. Tendo em vista o caráter diverso, dinâmico e contraditório das práticas de linguagem, a atuação confiante dos sujeitos nessas práticas demanda oportunidades de participar delas, conhecer como se estruturam e compreender como interagem na construção de identidades, pertencimentos, valores, e da vida pessoal e coletiva. (BRASIL, 2016, p.86, grifos nossos).

No fragmento destacado acima, além de nos reafirmar as relações de poder estabelecidas por meio da linguagem - as linguagens (...) podem gerar discriminação $e$ conflitos - e, consequentemente, a percepção sobre o preconceito linguístico, o documento ressalta o caráter diverso, dinâmico e contraditório das práticas de linguagem, possibilitando, assim, um espaço para as discussões referentes ao campo da Sociolinguística, especificamente no que tange às variações linguísticas, sobretudo por ressaltar este caráter diverso e dinâmico da língua, além de abordá-la a partir de seu uso, compreendendo-a como uma prática social.

Na seção seguinte, a partir da coleta de citações do documento, que nos serviram de exemplos, analisamos este lugar de reconhecimento das variações linguísticas, por meio de referências tanto indiretas como diretas, na Base Nacional Comum Curricular, para o tratamento da variação linguística.

\section{Análise dos Dados}

Como demonstrado anteriormente, os documentos parametrizadores do ensino partem, em suas concepções sobre a língua, de uma abordagem que privilegia o seu uso na esfera discursiva, possibilitando, assim, um espaço para as discussões referentes ao campo da Sociolinguística. Em concordância com esta premissa, a Base Nacional Comum Curricular (BNCC) faz e traz referências que situam o trabalho da variação linguística, na interface de ensino-aprendizagem, tanto indireta como diretamente. A própria utilização do termo linguagens, no plural, nos permite tais apontamentos sobre as variações linguísticas. Neste sentido, segue abaixo, a partir de uma leitura analítica do documento, trechos que mencionam este trabalho de forma indireta. 


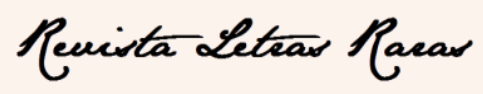

ISSN: $2317-2347$ - v. 7, n. 2 (2018)

Logo na parte introdutória do componente curricular Língua Portuguesa, na Educação Básica, o documento reconhece o dinamismo da língua, concebendo-a a partir de uma perspectiva que parte de seu uso na esfera social. Partindo desta premissa, no que se refere ao campo de ensino e aprendizagem, a Base ressalta que a instituição escolar deve comprometer-se com a multimodalidade de linguagens existentes no berço sociocultural, assegurando-a como um direito de aprendizagem do aluno. Como observamos no fragmento a seguir:

Exemplo 01:

A variedade de composição dos textos que articulam o verbal, o visual, o gestual, o sonoro, o tátil, que constituem o que se denomina multimodalidade de linguagens, deve também ser considerada nas práticas de letramento. A escola precisa, assim, comprometer-se com essa variedade de linguagens que se apresenta na TV, nos meios digitais, na imprensa, em livros didáticos e de literatura e outros suportes, tomando-as objetos de estudo a que os estudantes têm direito. (BRASIL, 2016, p.87, grifos nossos).

No fragmento acima, observamos a preocupação do documento com relação à diversidade de linguagem presente na esfera social. Implicitamente, o documento ressalta esta diversidade através das variedades da língua, as quais emergem a partir do suporte no qual ela se encontra veiculada. Em razão disto, a Base, embora de forma implícita, reconhece e concebe a língua como dotada de variações a depender da instância sociocomunicativa na qual o falante estiver inserido - essa variedade de linguagens que se apresenta na TV, nos meios digitais, na imprensa, em livros didáticos $e$ de literatura e outros suportes - além de assegurá-la como um direito de aprendizagem do aluno.

Ratificando este caráter discursivo e social da língua, a BNCC evidencia a importância do contexto, ou como se refere o documento, da situação discursiva, a qual está vinculada as relações de poder suscitados a partir da linguagem. Como nos demonstra o fragmento a seguir:

Exemplo 02:

Os enunciados ou textos são produzidos em uma situação de enunciação, determinada por condições históricas e sociais, por meio de discursos que instauram relações de poder. $\mathrm{O}$ aprendizado da leitura, da escrita e da oralidade culta envolve a compreensão dessas situações. (BRASIL, 2016, p.88, grifos nossos). 


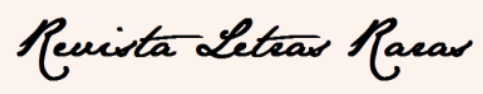

ISSN: $2317-2347$ - v. 7, n. 2 (2018)

Como observado no segundo exemplo, a BNCC suscita questões pertencentes ao campo da Sociolinguística, sobretudo quando o documento ressalta que "Os enunciados ou textos são produzidos (...) por meio de discursos que instauram relações de poder", estas relações de poder executadas em razão da e pela língua nos possibilita uma leitura alicerçada no campo das variações linguísticas, especificamente no que se refere à discriminação e ao preconceito linguístico, justificando, assim, a referência indireta à variação linguística, além do documento reiterar este posicionamento ao ressaltar as condições históricas e sociais pertencentes à língua.

Reafirmando este aspecto sociocultural da língua, ao contextualizar os Anos Finais do Ensino Fundamental, a BNCC ressalta que os alunos estão em uma fase de descentralização e ampliação dos conhecimentos, dentre eles, os linguísticos. Neste sentido, o documento destaca que se deve criar condições para que os discentes compreendam a pluralidade sociocultural que fomenta a língua. Como nos assegura o fragmento seguinte:

\section{Exemplo 03:}

O processo de descentralização, que caracteriza esse período de vida, amplia a capacidade dos/das estudantes, tanto de desenvolver sua autonomia, como de cultivar a alteridade. Desse modo, ao se potencializarem novas práticas nos diferentes componentes, também se criam condições para que os/as estudantes percebam a pluralidade sociocultural (artística, corporal e linguística) e as relações entre linguagens, identidades e pertencimentos, alargando as possibilidades de ser e de interagir com grupos sociais. (BRASIL, 2016, p.325, grifos nossos).

No fragmento acima, a Base retoma a concepção de pluralidade sociocultural ao referir-se às linguagens - artística, corporal e linguística - ressaltando os aspectos identitários que a caracterizam. Neste sentido, percebemos menção à variação linguística, mesmo que implicitamente, quando o documento menciona "as possibilidades de ser e de interagir com grupos sociais", tendo em vista que estes grupos sociais são constituídos por um falar característico, isto é, por uma forma linguística identitária, a qual demarca a interação e o pertencimento de seus sujeitos por marcações também linguísticas. No campo da Sociolinguística, esta concepção linguística identitária, neste caso, refere-se, especialmente, à variação diastrática (ALKMIM, 2004; CAMACHO, 2004), a qual caracteriza os grupos/tribos sociais por meio das marcas linguísticas. 


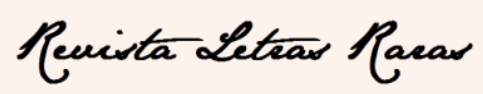

ISSN: $2317-2347$ - v. 7, n. 2 (2018)

Assim como exposto nos exemplos acima, o documento analisado também nos possibilita este reconhecimento do trabalho com a variação linguística de forma explícita. Os fragmentos seguintes exemplificam as menções à variação linguística de forma direta na BNCC.

$\mathrm{Na}$ área de Linguagens, especificamente no componente curricular Língua Portuguesa, o trabalho com a variação linguística é ressaltado como um dos seis objetivos gerais da Educação Básica, isto é, na modalidade educacional há uma preocupação sobre este fator inerente às línguas (LABOV, 2008; TARALLO, 2002). Este falar é assegurado e ressaltado como um direito de aprendizagem do aluno. Como nos assegura o fragmento seguinte:

Exemplo 04:

6) Compreender que a variação linguística é um fenômeno que constitui a linguagem, reconhecendo as relações de poder e as formas de dominação e preconceito que se fazem na e pela linguagem e refletindo sobre as relações entre fala e escrita em diferentes gêneros, assim como reconhecer e utilizar estratégias de marcação do nível de formalidade dos textos em suas produções. (BRASIL, 2016, p.98).

No fragmento acima, observa-se, explicitamente, o reconhecimento da variação linguística enquanto fenômeno inerente à língua. Além disto, a BNCC ressalta as relações entre fala e escrita em diferentes gêneros, isto é, a adequação linguística de acordo com o contexto interacional. É válido destacar que o documento reafirma o nosso posicionamento, exposto anteriormente, ao afirmar que as relações de poder e as formas de dominação e preconceito que se fazem na e pela linguagem, ou seja, conceitos caros para a variação linguística, especificamente no que se refere ao preconceito linguístico, uma vez que os atos discursivos instauram estas relações de poder entre os interlocutores, como também as formas de discriminação em razão das escolhas linguísticas. Partindo destas considerações, o documento assegura o trabalho deste fenômeno como um dos objetivos da Educação Básica, a qual engloba desde a Educação Infantil até o Ensino Médio9.

\footnotetext{
${ }^{9}$ Em sua terceira e última versão revista (2017), o documento não divulgou questões referentes ao Ensino Médio.
} 


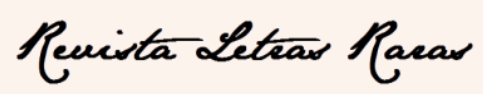

ISSN: $2317-2347$ - v. 7, n. 2 (2018)

Da mesma maneira demonstrada acima, no quarto eixo linguístico, o qual se refere ao Conhecimento sobre a Língua e sobre a Norma ${ }^{10}$, a Base defende a importância da compreensão e reflexão sobre a língua e sobre as variações que a constitui. Como nos exemplifica o fragmento seguinte, relativo aos objetivos gerais pensados para este eixo:

Exemplo 05:

Compreender a condição social e histórica da língua como polissistema dinâmico e variável;

Refletir sobre a variação de registro e sobre a variação regional e social da língua. (BRASIL, 2016, p.366, grifos nossos).

Como observamos no exemplo acima, a Base refere-se, de forma direta, aos níveis de análise das variações linguísticas - variação de registro- diafásica; variação regional-diatópica; e a social - diastrática - além de caracterizar a língua como sendo um polissistema dinâmico e variável, demarcando estes conhecimentos como objetivos dos anos finais do Ensino Fundamental, os quais devem ser abordados em uma perspectiva de progressão, isto é, devem acompanhar o estudante gradativamente na sua formação escolar, desde o $6^{\circ}$ ao $9^{\circ}$ ano.

É válido ressaltar que este eixo, de acordo com o documento, deve ser trabalhado de forma conjunta com os outros três - leitura, escrita e oralidade/sinalização. Em razão disto, esta vinculação dos conteúdos da variação linguística com o presente eixo, nos leva a inferir que este trabalho também deve dialogar com os referidos eixos, tendo em vista que há uma escrita adequada a uma dada situação, assim como há uma fala adequada em dado contexto sociocomunicativo. Assim, essa interação nos permite perceber que os trabalhos sobre os conhecimentos linguísticos não devem ser trabalhados de forma isolada, mas, sim, em uma perspectiva multidisciplinar, que promova um diálogo efetivo no contexto de sala de aula, promovendo, consequentemente, uma construção plena do saber sobre a língua para com o alunado.

Além desse objetivo analisado anteriormente, também percebemos outras menções ao lugar da variação linguística no documento, tanto no eixo Leitura como

\footnotetext{
${ }^{10} \mathrm{Na}$ terceira e última versão, o documento adota a terminologia Conhecimentos Linguísticos e Gramaticais (BRASIL, 2017), que, em sua essência, manteve as mesmas preocupações que o eixo Conhecimento sobre a Língua e sobre a Norma aqui analisado.
} 


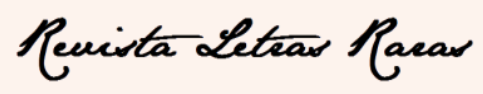

ISSN: $2317-2347$ - v. 7, n. 2 (2018)

Escrita, muito embora observamos que estas menções são bem pontuais. Como mostram os exemplos que seguem:

Exemplo 06:

Analisar aspectos linguísticos e textuais de novas formas de escrita da internet, em registro informal, que vêm se denominando "internetês". (BRASIL, 2016, p.334, grifos nossos).

No exemplo acima, a Base ressalta a importância da adequação linguística em razão do internetês, caracterizando-o como uma "escrita da internet, em registro informal". Neste sentido, o documento pontua esta variação (no nível diafásico), em virtude da plataforma virtual, como um objetivo a ser trabalhado tanto no eixo Leitura como Escrita, principalmente para o aluno adequar-se linguisticamente ao contexto sociocomunicativo da Internet.

Da mesma maneira como foi exposto anteriormente, o eixo Escrita, além de reafirmar os registros linguísticos representados pelo internetês, destaca a importância das escolhas linguísticas frente ao contexto de interação, isto é, menciona a importância da adequação linguística em dado contexto comunicacional. Como nos exemplifica o fragmento a seguir:

\section{Exemplo 07:}

Refletir sobre o endereçamento dos textos e sobre as escolhas linguísticas adequadas à interlocução proposta. (BRASIL, 2016, p.351, grifos nossos).

No fragmento acima, observa-se que a BNCC reconhece a importância tanto do endereçamento dos textos como as escolhas linguísticas enquanto fatores determinantes no processo de interlocução. Com relação a essas escolhas linguísticas, o documento destaca que estas devem estar adequadas à interlocução proposta, reafirmando, assim, a importância da adequação linguística ao contexto interacional, além de ressaltar o papel das variações linguísticas, seja no âmbito virtual, seja no social.

Retornando ao eixo Conhecimento sobre a Língua e a Norma, especificamente com relação ao vínculo entre os conteúdos da variação linguística e o referido eixo, percebemos a importância do entendimento com relação à terminologia norma, tendo em vista o impacto de tal nomenclatura nos processos de ensino e aprendizagem, uma vez que esta pode ser compreendida tanto na perspectiva do normal como na perspectiva no normativo (BAGNO, 2012;2002;2001), e, em razão disto, tal acepção 


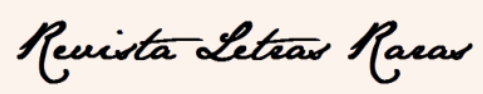

ISSN: 2317-2347 - v. 7, n. 2 (2018)

pode suscitar atitudes enraizadas na abordagem tradicional, fomentando, assim, o preconceito linguístico, contrapondo-se com o que as variações linguísticas preconizam e com o que está sendo defendido na Base. Neste sentido, enfatizamos a importância do papel tanto dos currículos como dos professores de língua materna, os quais serão determinantes para o trabalho destas questões linguísticas no campo educacional.

\section{Considerações Finais}

A partir do exposto, percebemos que há sim um lugar pensado para o trabalho com a variação linguística na Base Nacional Comum Curricular, o qual é assegurado e demarcado como um direito de aprendizagem do aluno na Educação Básica, tanto é que este trabalho é apresentado como um dos seis objetivos que fundamentam e norteiam a Educação Básica - a qual engloba e perpassa a Educação Infantil e todo o Ensino Fundamental e o Ensino Médio.

Entendemos que agora vamos viver o momento da implementação desse documento no ambiente escolar, sendo assim caberá às escolas, via currículo especificamente, trazer para o seio escolar ações que não somente reconheçam as variação linguística em sua essência, mas acima de tudo as respeitem e combatam todo tipo de preconceito linguístico, dentro e fora da sala de aula, conforme defende a BNCC em seus postulados.

Ressaltamos, também, que a postura do profissional docente é determinante no processo de ensino-aprendizagem, principalmente com relação à abordagem do estudo da variação linguística, pois, caso este profissional não tenha o perfil almejado e adequado, perpetuará, como um rito, a tradição que embasa as nossas instituições escolares há décadas sob uma nova nomenclatura, mas com uma postura educacional fundamentada no mesmo paradigma educacional, o qual privilegia um ensino mecanicista e cartesiano, sem considerar a dinamicidade linguística, classificando, assim, as variações linguísticas como um desvio da "pureza linguística", as quais devem ser evitadas em nome da boa escrita e da boa fala.

Por esta pesquisa ter sido realizada sem a implementação efetiva do documento, enfatizamos que, em razão desta ausência de aplicação metodológica, questionamentos como a aplicabilidade das concepções propostas na Base se fazem necessários, 


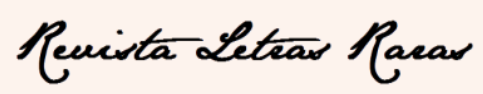

ISSN: 2317-2347 - v. 7, n. 2 (2018)

principalmente com relação à variação linguística na interface de ensino-aprendizagem, os quais lançamos como norteadores para projetos futuros.

\section{REFERÊNCIAS}

ANDRÉ, Marli Eliza Dalmazo Afonso. Etnografia da prática escolar. Campinas: Papirus, 1995.

ALKMIM, Tânia. Sociolinguística - parte I. In: MUSSALIM, Fernanda; BENTES, Anna Christina. (orgs.). Introdução à linguística - domínios e fronteiras. 4 ed. São Paulo: Cortez, 2004. p. 21-48.

ANTUNES, Irandé. Muito além da gramática: por um ensino de línguas sem pedras no caminho. São Paulo: Parábola Editorial, 2007.

ARROYO, Miguel G. Currículo, território em disputa. Petrópolis: Vozes, 2013.

Bagno, Marcos. Norma Linguística, Hibridismo e Tradução. Disponível em: < http://repositorio.unb.br/>. Acesso em: 28 de junho de 2017.

Nada na língua é por acaso - por uma pedagogia da variação linguística. São Paulo: Parábola, 2007.

. (org. ). Linguística da Norma. São Paulo: Loyola, 2002.

. (org.). Norma Linguística. São Paulo: Loyola, 2001.

BRASIL. Constituição da República Federativa do Brasil. Promulgada em 05 de outubro de 1988. Disponível em: <www.planalto.gov.br/>. Acesso em: 23 janeiro 2017.

Base Nacional Comum Curricular. Disponível em:

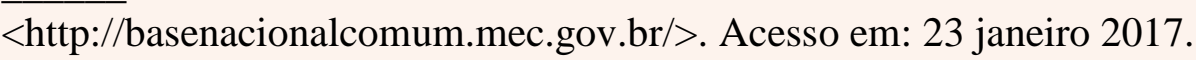

Lei 9394/96 - Lei de Diretrizes e Bases da Educação Nacional. Disponível em: <www.planalto.gov.br >. Acesso em: 23 janeiro 2017.

BEZERRA, Maria A.; DIONİSIO, Ângela P.; MACHADO, Anna R. (orgs.). Gêneros textuais e ensino. São Paulo: Parábola, 2010.

CAMACHO, Roberto G. Sociolinguística - parte II. In: MUSSALIM, Fernanda; BENTES, Anna Chistina. (orgs.). Introdução à linguística - domínios e fronteiras. 4 ed. São Paulo: Cortez, 2004. p. 49-76.

FARACO, Carlos A. Norma culta brasileira - desatando alguns nós. São Paulo: Parábola, 2008.

HORA, Dermeval. (org.). Estudos sociolinguísticos: perfil de uma comunidade. Rio Grande do Sul: Pallotti, 2004.

IANNI, O. Língua e sociedade. In: VALENTE, A. (org.). Aulas de Português: perspectivas inovadoras. Petrópolis: Vozes, 1999. p. 11-44.

LABOV, William. Padrões sociolinguísticos. São Paulo: Parábola, 2008. 


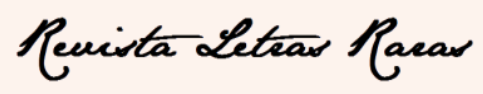

ISSN: 2317-2347 - v. 7, n. 2 (2018)

LEAL, Maria Auxiliadora da F. O ensino do português na escola atual: análise de alguns fenômenos de mudança. In: DELL'ISOLA, Regina; MENDONÇA, Eliana. Reflexões sobre a língua portuguesa - ensino e pesquisa. Campinas: Pontes, 1997. p.1524.

LEITE, Marli Q. Variação linguística: dialetos, registros e norma linguística. In: SILVA, Luiz Antônio da. Português: história, variação e discurso. São Paulo: Globo, 2005. p. 183-210.

MOLLICA, Maria Cecília; BRAGA, Maria Luiza. (orgs.). Introdução à sociolinguística - o tratamento da variação. São Paulo: Contexto, 2004.

TARALLO, Fernando. A pesquisa sociolinguística. 8 ed. São Paulo: Ática, 2007.

TRAVAGLIA, Luiz C.. Gramática e interação: uma proposta para o ensino de gramática no $1^{\circ}$ e $2^{\circ}$ graus. 8. ed. São Paulo: Cortez, 2002.

Recebimento: 16/05/2018

Aceite: 08/09/2018 